\title{
Impact of glutathione peroxidase 4 on cell proliferation, angiogenesis and cytokine production in hepatocellular carcinoma
}

\author{
Nataliya Rohr-Udilova ${ }^{1}$, Eva Bauer ${ }^{2}$, Gerald Timelthaler $^{3}$, Robert Eferl ${ }^{3}$, Klaus \\ Stolze ${ }^{4,5}$, Matthias Pinter ${ }^{1}$, Martha Seif ${ }^{1}$, Hubert Hayden ${ }^{1}$, Thomas Reiberger $^{1}$, Rolf \\ Schulte-Hermann ${ }^{3}$, Markus Peck-Radosavljevic ${ }^{1,6}$, Dagmar Stoiber ${ }^{2,7, *}$ and Michael \\ Trauner $^{1, *}$ \\ ${ }^{1}$ Division of Gastroenterology and Hepatology, Internal Medicine III, Medical University of Vienna, Vienna, Austria \\ ${ }^{2}$ Ludwig Boltzmann Institute for Cancer Research, Vienna, Austria \\ ${ }^{3}$ Institute of Cancer Research, Internal Medicine I, Medical University of Vienna, Vienna, Austria \\ ${ }^{4}$ Department of Life Sciences, Veterinary University of Vienna, Vienna, Austria \\ ${ }^{5}$ Institute of Animal Nutrition and Functional Plan Compounds, Department of Farm Animals and Veterinary Public Health, \\ Veterinary University of Vienna, Vienna, Austria \\ ${ }^{6}$ Clinic Klagenfurth, Division of Gastroenterology and Hepatology, Klagenfurt am Woerthersee, Austria \\ ${ }^{7}$ Institute of Pharmacology, Center for Physiology and Pharmacology, Medical University of Vienna, Vienna, Austria \\ *These authors contributed equally to this work
}

Correspondence to: Nataliya Rohr-Udilova, email: nataliya.rohr-udilova@meduniwien.ac.at

Keywords: phospholipid glutathione peroxidase; free radicals; cell proliferation; angiogenesis; hepatocellular carcinoma

Received: August 12, $2017 \quad$ Accepted: November 16, $2017 \quad$ Published: January 22, 2018

Copyright: Rohr-Udilova et al. This is an open-access article distributed under the terms of the Creative Commons Attribution License 3.0 (CC BY 3.0), which permits unrestricted use, distribution, and reproduction in any medium, provided the original author and source are credited.

\section{ABSTRACT}

Insufficient supplementation with the micronutrient selenium and persistent hepatic inflammation predispose to hepatocellular carcinoma (HCC). Inflammationassociated reactive oxygen species attack membrane lipids and form lipid hydroperoxides able to propagate oxidative hepatic damage. Selenium-containing enzyme glutathione peroxidase 4 (GPX4) antagonizes this damage by reducing lipid hydroperoxides to respective hydroxides. However, the role of GPX4 in HCC remains elusive.

We generated two human HCC cell lines with stable overexpression of GPx4, performed xenotransplantation into NOD.Cg-Prkdc ${ }^{\text {scid } I l} 2$ rg $^{\text {tm1 } 1 w_{j l}} /$ SzJ (NSG) host mice and characterized the tumors formed. The experimental data were verified using gene expression data from two independent HCC patient cohorts.

GPX4 overexpression protected from oxidative stress and reduced intracellular free radical level. GPx4-overexpressing cells displayed impaired tumor growth, reduced proliferation, altered angiogenesis and decreased expression of clinically relevant cytokine interleukin-8 and C-reactive protein. Moreover, GPx4 overexpression impaired migration of endothelial cells in vitro, and enhanced expression of thrombospondin 1, an endogenous inhibitor of angiogenesis. In patients, GPX4 expression in tumors positively correlated with survival and was linked to pathways which regulate cell proliferation, motility, tissue remodelling, immune response and M1 macrophage polarization. The patient data largely confirmed experimental findings especially in a subclass of poor prognosis tumors with high proliferation.

GPx4 suppresses formation and progression of HCC by inhibition of angiogenesis and tumor cell proliferation as well as by immune-mediated mechanisms. Modification of GPx4 expression may represent a novel tool for HCC prevention or treatment. 


\section{INTRODUCTION}

Hepatocellular carcinoma (HCC) is the second leading cause of cancer-related deaths worldwide [1]. $\mathrm{HCC}$ epidemiology is currently changing due to the availability of highly-effective antiviral drugs against $\mathrm{HBV}$ and HCV infections as well as due to increasing incidence of other cancer-predisposing liver diseases such as alcoholic and non-alcoholic steatohepatitis (ASH, NASH) and non-alcoholic fatty liver disease (NAFLD) [2].

Chronic hepatic inflammation is a common feature of cancer-predisposing liver diseases and favours HCC development [3]. There is a broad consensus that oxidative stress mediated by reactive oxygen species (ROS) plays a pivotal role [4]. Oxidative stress may not only interfere with cellular homeostasis and metabolism but also contributes to lipotoxicity. ROS initiate peroxidation of polyunsaturated fatty acids resulting in formation of fatty acid hydroperoxides, as shown for heating of dietary oils or inflammation [5]. Fatty acid hydroperoxides can undergo Fenton-type decomposition thus increasing intracellular radical level, propagating lipid peroxidation and favouring mutagenesis and regenerative cell proliferation.

We have previously found that linoleic acid hydroperoxide apparently contributes to NASH and HCC and that selenium antagonises the effects in $\mathrm{HCC}[6,7]$. In line, selenium inversely correlates with tumor size in Austrian HCC patients [7]. Moreover, epidemiological studies revealed an increased HCC risk in patients with low systemic levels of selenium [8-10] whereas selenium supplementation decreased the risk [10].

Selenium as selenocysteine is present in the catalytic centre of antioxidative enzymes. Five of the 25 characterized human selenoproteins belong to a family of glutathione peroxidases which reduce hydroperoxides to the respective alcohols by oxidation of two glutathione molecules [11]. Hydroperoxides are cytotoxic at higher concentrations while lower concentrations are essential for intra- and extracellular signalling and adequate immune response [12].

Glutathione peroxidase $4(\mathrm{GPx} 4)$ is essential for life at least in mice [13]. The unique function of GPx4 consists in reduction of lipid hydroperoxides within membranes thus preventing formation of secondary radicals [14] and inhibiting further lipid peroxidation [11]. The expression and activity of GPx4 depends on selenium [15]. The liver is particularly sensitive to moderate selenium deficiency since other organs such as brain and reproductive system take up selenium with higher priority [15].

In a previous mechanistic study, we found inverse relations between lipid hydroperoxides and selenium levels in hepatocarcinogenesis [7]. Inhibition of GPx4 expression by siRNA in HCC cells increased formation of cytokines VEGF and IL-8 [7] both of which are clinically relevant adverse prognostic factors in HCC patients [16, 17].
Complementary to our previous study [7], we now assessed the effects of GPx4 overexpression in HCC and analysed correlations between GPx4 and cancer patient survival. Further, we have re-evaluated gene expression microarray data from 140 human HCCs and conducted pathway analyses. Finally, a new system biology approach allowed us to analyze and to compare the composition of infiltrating immune cells in human HCC tumors stratified according to the intratumoral GPx4 levels.

Data from humans confirmed the experimental data obtained in cell culture and animal xenografts. Results of molecular, biochemical and histological studies clearly support the protective role of GPx4 in liver carcinogenesis. Our results indicate that GPx4 inhibits cell proliferation, migration, angiogenesis and immune cell infiltration. An increase of GPx4 activity may represent a novel tool for HCC treatment or prevention.

\section{RESULTS}

\section{In vitro characterisation of $\mathrm{HCC}$ cells overexpressing GPx4}

To explore GPx4 functions in HCC, we introduced the porcine GPx4 gene into the human HCC3 cell line. Western blotting, real-time RT-PCR and activity measurements confirmed GPx4 overexpression (Figure 1A). GPx4 overexpressing cells were more resistant to cell death induced by hydrogen peroxide and peroxidized linoleic acid ( $\mathrm{LOOH}$, Figure 1B, 1C). Notably, GPx4 overexpression reduced intracellular radical level as demonstrated by two independent methods (Figure 1D, 1E). In line with diminished radical stress, we found increased intracellular glutathione concentrations in cells overexpressing GPx4 (Figure 1F).

Down-regulation of GPx4 in hepatocarcinoma cells induces VEGF and IL-8 [7], the two cytokines associated with poor HCC prognosis [16, 17]. Complementary, overexpression of GPx4 in HCC tumor cells lowered IL-8 levels at base line and upon $\mathrm{LOOH}$ treatment (Figure 2A, 2B). In contrast, VEGF mRNA and protein levels remained constant (Figure 2A, 2B).

We have previously shown that $\mathrm{LOOH}$ induce HCC cell cycle progression [18]. Consistently, GPx4 overexpression reduced the $\mathrm{LOOH}$-induced increase of cells in G2/M phase (Figure 2C). Furthermore, GPx4 inhibited HCC cell proliferation as indicated by a decreased mRNA of the proliferation marker KI-67 (Figure 2D) as well as by BrdU incorporation (Figure 2E, 2F). In addition, supernatants from GPx4 overexpressing HCC-3 cells treated by LOOH showed a decreased capacity to induce the migration of HUVECs (Supplementary Figure 2). 


\section{Effect of GPx4 overexpression on in vivo tumor growth in a xenograft model}

In vivo effects of GPx4 overexpression were addressed in a xenograft NSG mouse model. GPx4 overexpression persisted in xenograft tumors (Figure 3A). GPx4-overexpressing HCC-3 derived tumors grew slower as compared to vector transfected cells and exhibited reduced final tumor weight (Figure 3B). In line with cell culture in vitro experiments (Figure 1F, Figure 2D-2F), we found elevated glutathione (GSH) levels (Figure 3C) as well as reduced cell proliferation (Figure 3D) in GPx4overexpressing tumors.

\section{GPx4 overexpression and angiogenesis in HCC-3 tumors}

Xenograft tumors overexpressing GPx4 exhibited an increased vessel density but decreased vessel diameter and wall thickness (Figure 4A). Small and medium vessels prevailed in tumors with GPx4 overexpression (Figure 4B).

Interestingly, vessel wall thickness correlated with the percentage of large vessels (Supplementary Figure 3A). Moreover, other vessel parameters as vessel size, vessel wall thickness and percentage of large vessels also correlated with tumor volume (Supplementary
A

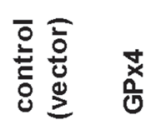

GPx4 ( 21kDa)

GAPDH

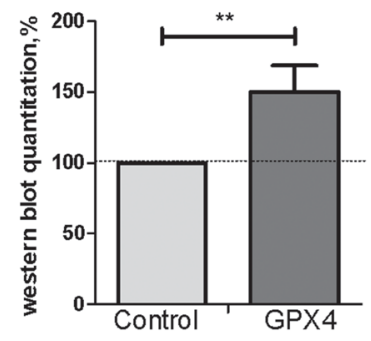

B

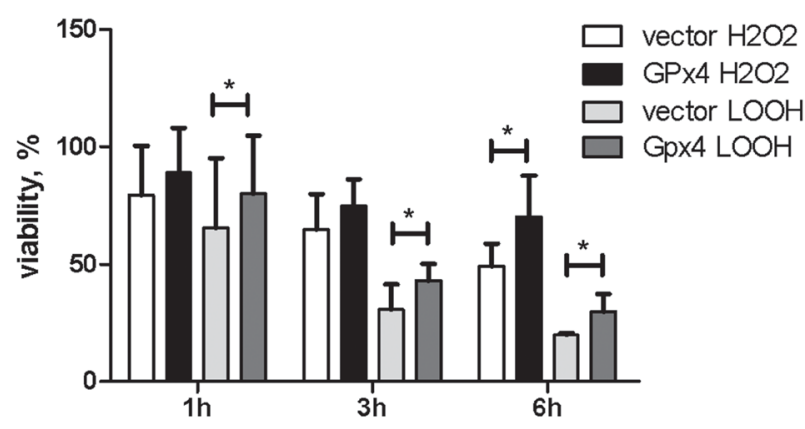

D

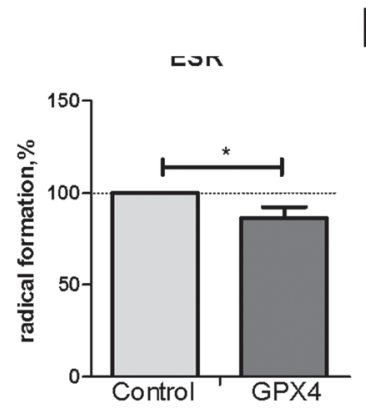

E

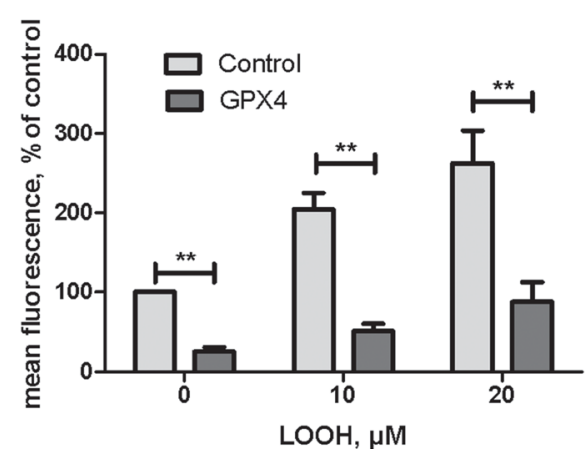

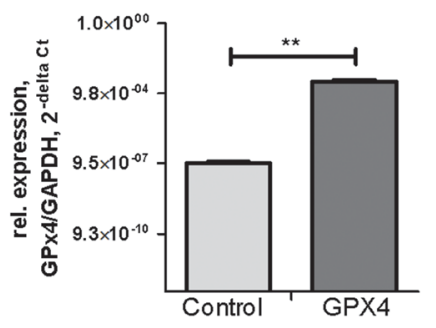
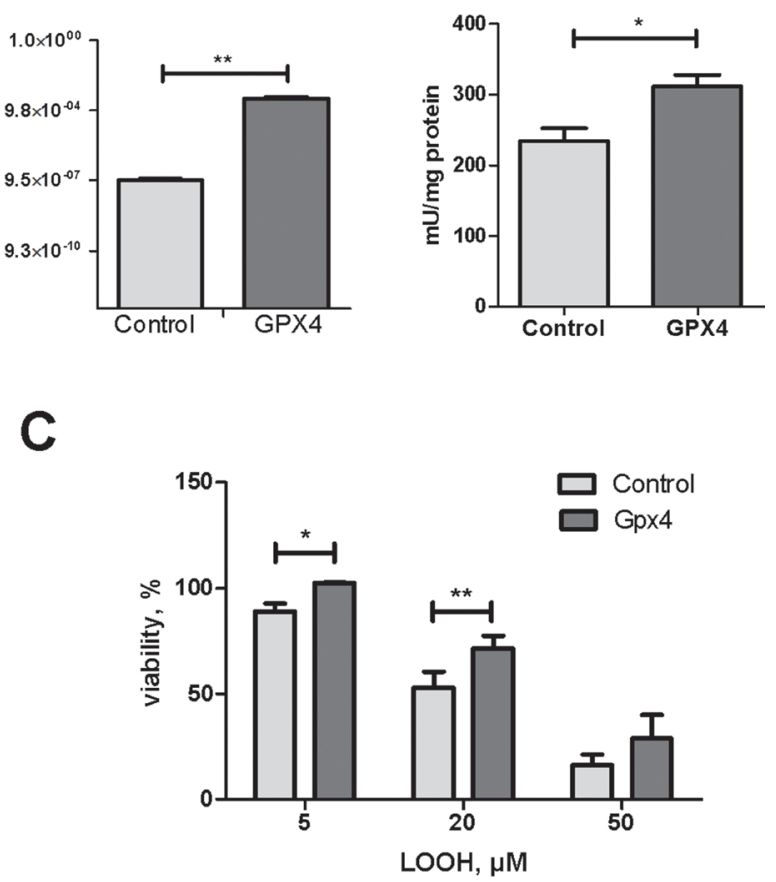

$\mathbf{F}$

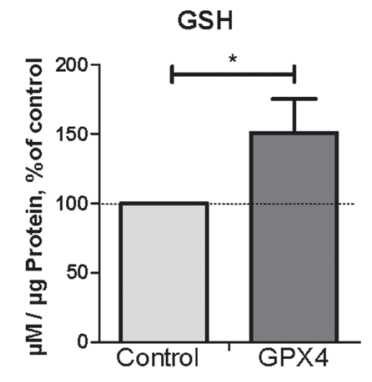

Figure 1: Characterisation of HCC-3 cells overexpressing GPx4. (A) A representative western blot, quantification summary, mRNA levels and activity in GPx4-transfected HCC-3 cells (Gpx4); control (vector), ${ }^{* *} p<0.01$; ${ }^{*} p<0.05$. (B) HCC-3 control (vector) or GPx4 overexpressing cells were incubated with $200 \mu \mathrm{M} \mathrm{H}_{2} \mathrm{O}_{2}$ or with $30 \mu \mathrm{M} \mathrm{LOOH}$ for the indicated time and viable cells quantified with neutral red. (C) HCC-3 were incubated with $\mathrm{LOOH}$ for $24 \mathrm{~h}$ and viability was assessed. (D) HCC-3 cells were mixed with CMH and analysed by ESR spectroscopy as described in supplementary Materials and Methods. Three independent cell preparations were measured in three repeats each and summarized. (E) $10^{5} \mathrm{HCC}-3$ cells were incubated with LOOH for $2 \mathrm{~h}$ in the presence of DCFH. Intracellular mean fluorescence was quantified by flow cytometry. (F) Intracellular GSH concentration in control and GPx4 overexpressing HCC-3 cells was determined as described in Materials and Methods. 
Figure 3B). These results imply that larger vessels with thicker wall support tumor growth more efficiently while GPx4 overexpression constrains growth of large tumor vessels.

To investigate potential regulators of the observed angiogenic pattern, we focused on thrombospondin 1 (THBS1), an endogenous inhibitor of angiogenesis [19]. Indeed, GPx4 overexpression increased THBS1 expression in tumors and cultured cells (Figure 4C-4E, Supplementary Figure 4A), whereas VEGF expression remained constant (Figure 4C-4E).
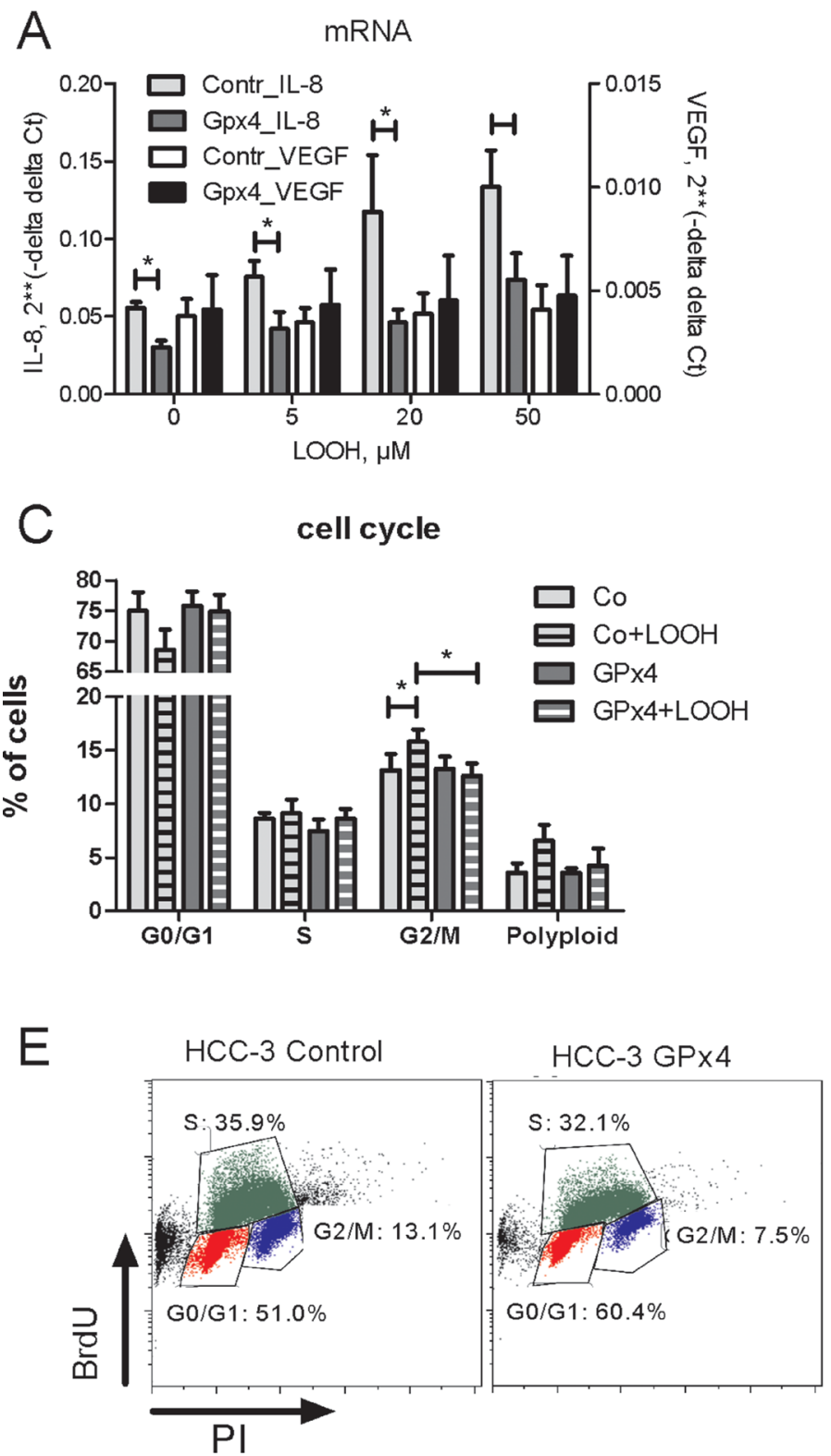

\section{GPx4 overexpression and formation of IL-8 and C-reactive proteins}

Tumor-associated macrophages promote tumor angiogenesis [20]. We found that GPx4 overexpression reduced the density of F4/80 positive macrophages in xenografts (Figure 5A).

Importantly, IL-8 exerts chemotactic activity on lymphocytes and neutrophils [20]. Neutrophils, in turn, recruit macrophages thus stimulating tumor growth [21]. In addition to IL-8, C-reactive protein (CRP) also
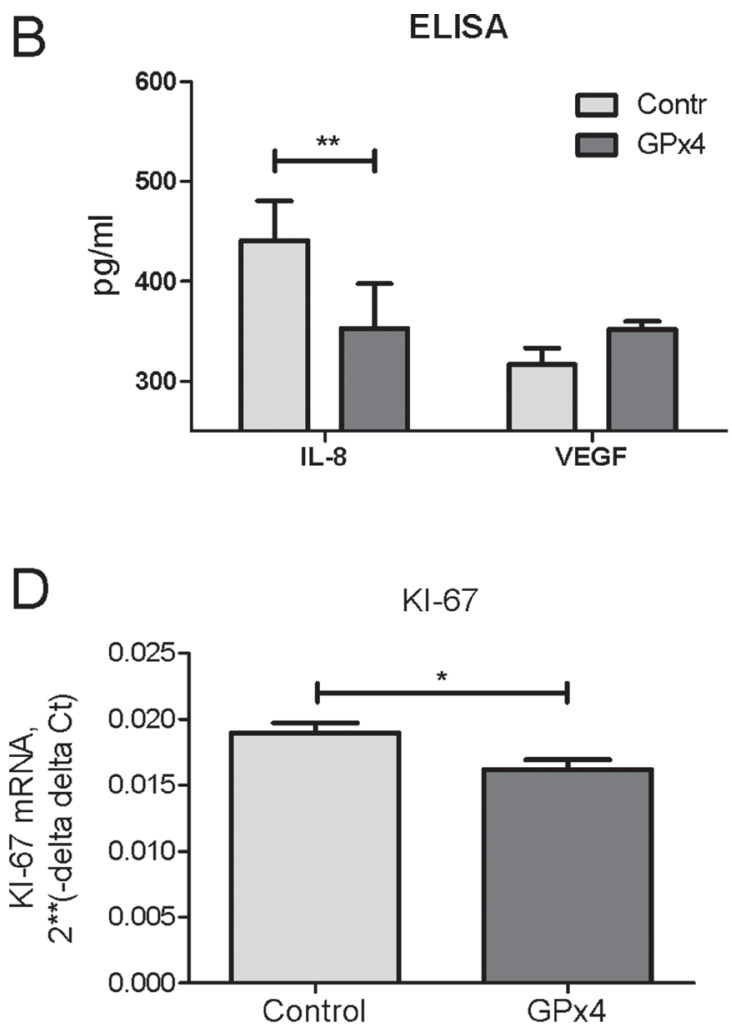

$\mathrm{F}$

HCC-3: BrdU

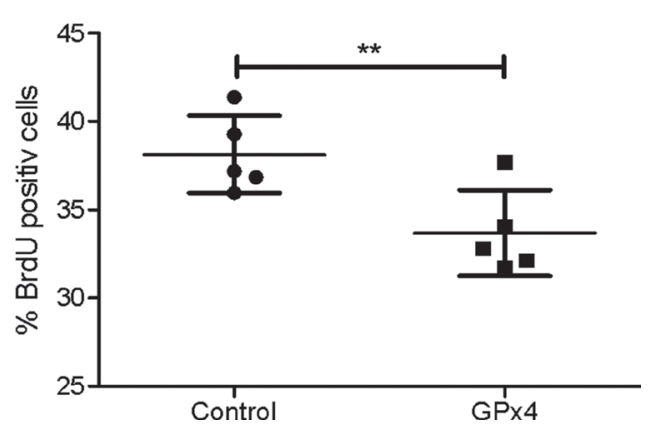

Figure 2: Impact of Gpx4 overexpression on gene expression and cell cycle progression in $\mathrm{HCC}-3$ cells. (A) GPx 4 overexpressing (GPx4) or control (vector) HCC-3 cells were treated by LOOH for 3 hours and IL-8 mRNA and VEGF mRNA were analysed by real-time RT-PCR. (B) Protein concentrations of IL-8 and VEGF in supernatants of HCC-3 cells (6 h). (C) Cell cycle progression in HCC cells treated by $20 \mu \mathrm{M} \mathrm{LOOH}$ or by vehicle for 3 hours. (D) HCC-3 cells $\left(3 \times 10^{5} /\right.$ well) were seeded into 6 well plates and KI-67 mRNA was analysed by real-time RT-PCR $24 \mathrm{~h}$ later. (E) Impact of GPx4 overexpression in HCC-3 cells on BrdU incorporation: representative plot for HCC-3 control and HCC-3 GPx4 overexpressing cells. (F) Quantitation summary of BrdU incorporation. ${ }^{*} p<0.05 ;{ }^{* *} p<0.01$. 
facilitates macrophage infiltration and has clinically prognostic value in HCC [22]. GPx4 overexpression reduced the concentrations of both, serum IL-8 and CRP proteins in the xenograft model (Figure 5B, 5C). Both, serum IL-8 and CRP, correlated with tumor size and with macrophage infiltration (Figure 5D-5G). Decreased CRP
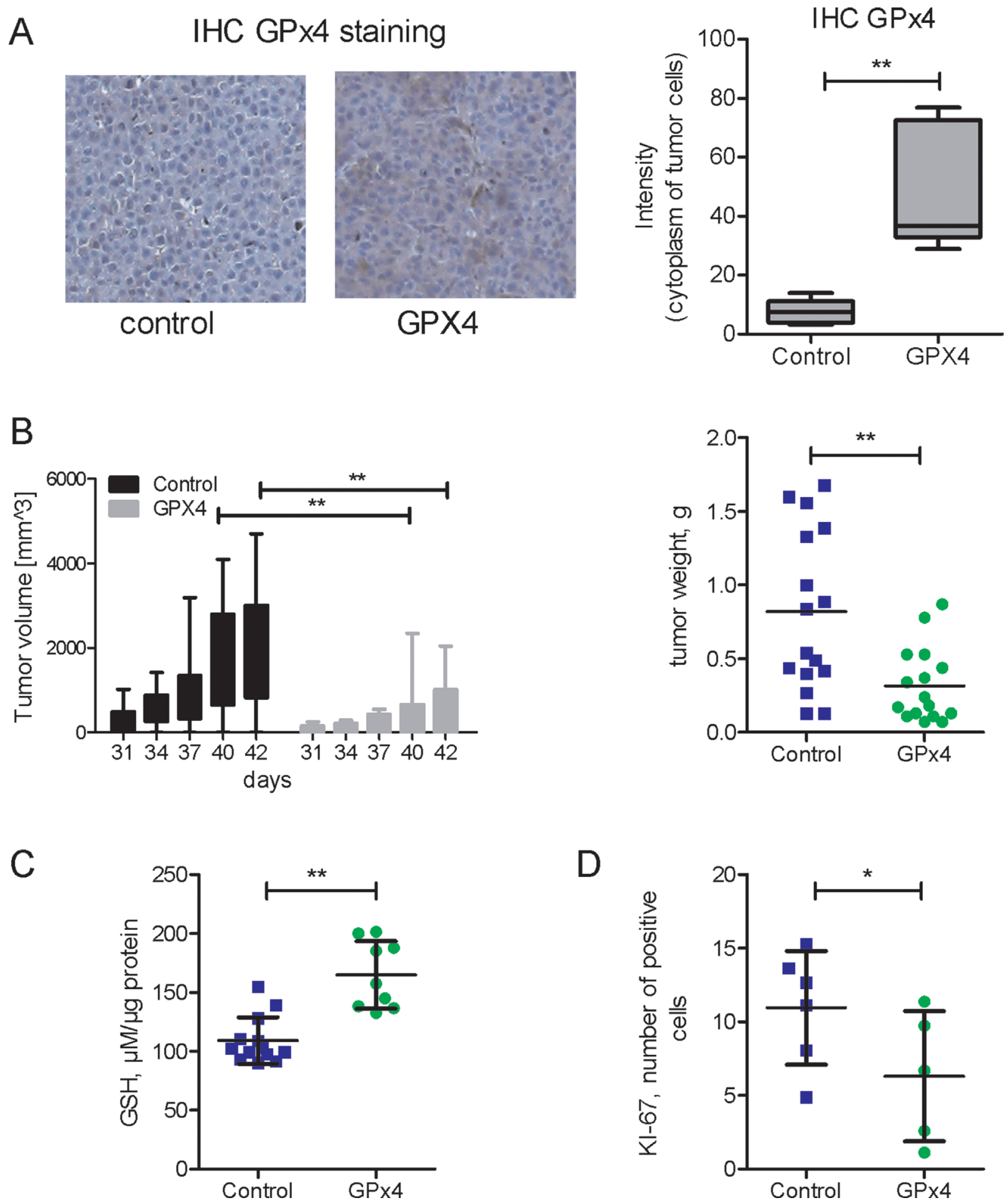

Figure 3: In vivo growth of xenograft HCC tumors overexpressing GP x 4. (A) IHC GP x 4 staining and histomorphometric analysis of GP x 4 staining intensity in xenograft tumors originating from HCC-3 cells, either control-vector or overexpressing GP x 4 (GP x 4). $\left(n=5\right.$ per group, $\left.{ }^{* *} p<0.01\right)$ (B) Growth kinetics (days) and final weight of xenograft tumors $\left(n=16\right.$ in each group, $\left.{ }^{* *} p<0.01\right)$. For subsequent investigations, the tumors were harvested at the end of experiment on day 42. (C) Glutathione content in lysates of GP $\mathrm{x}$ 4 overexpressing and control (vector) tumors $(n=9-13, p<0.01)$. (D) Histomorphometric analysis of KI-67-positive cells in xenograft tumors $(n=5-6, p<0.05)$. 
expression was confirmed in vitro in GPx4 overexpressing HCC-3 cells (Supplementary Figure 4B).

The key results obtained with GPx4 overexpressing HCC-3 cells were confirmed in the second transfected human HCC cell line, Huh7. Tumors originating from GPx4 overexpressing Huh7 cells were smaller, had higher glutathione content, increased THBS1 and decreased CRP expression as well as altered angiogenic pattern (Supplementary Figure 5).

\section{Confirmation of GPx4 effects in human HCC}

To check the relevance of the above experimental findings for humans, we investigated associations between survival of cancer patients and mRNA levels of GPx4 and 23 other selenoproteins. We applied the recently established Prediction of Clinical Outcome from Genomic Profiles (PRECOG) database which combines survival and microarray gene expression data from $\sim 18000$ cancer patients [23].

GPx4 is the only selenoprotein which is consistently associated with a prolonged survival in cancer including HCC (Supplementary Table 1, Supplementary Figure 6).

To further explore the role of GPx4 in human HCC and to strengthen the significance of our experimental findings, we re-evaluated microarray gene expression from two independent HCC patient cohorts: i) $n=60$ [24] and ii) $n=80$ [25]. Natural variations of GPx4 expression allowed us to stratify the patients according to their GPx4 level. Using median as a cut-off value, we separated the "low GPx4" and the "high GPx4" patient groups and compared the mean expression values of THBS1, KI-67, CRP, VEGF, IL-8 and human F4/80 homolog EMR1 between the groups.
Since HCC tumors are extremely heterogeneous, molecular HCC subclasses S1, S2 and S3 specify patients with similar deregulated pathways and similar prognosis. In particular, patients with S1 and S2 subclass tumors have poor prognosis as compared to S3 subclass [25].

To assess the role of GPx4 in different molecular backgrounds, we additionally compared the differences between low and high GPx4 expression for each molecular subclass. Interestingly, GPx4 expression was lower in the proliferation subclass S2 than in S1 $(p<0.05)$ and S3 (trend, $p=0.078$ ) (Figure 6A). The "high GPx4" group within the S2 subclass showed a decreased expression of EMR1/F4/80, KI-67 and VEGF as well as an increased expression of THBS1 as compared to the "low GPx4" group (Figure 6B-6E). The whole cohorts showed less pronounced but similar changes. Down-regulation of CRP and IL- 8 by experimental GPx4 overexpression was recapitulated in the "high GPx4" patient group and particularly within the S1 subclass (Supplementary Figure 7A, 7B).

We have further compared relative GPx4 expression between tumor tissue and surrounding tissue in $\mathrm{HCC}$ patients with different molecular subclasses. As Figure $6 \mathrm{~F}$ shows, GPx4 level in surrounding tissue differs from that in tumor. In particular, S3 subclass with a better prognosis showed higher GPx4 level in tumors than in corresponding surrounding tissues. In contrast, S2 subclass showed an opposite trend: higher GPx4 level in surrounding tissues than in tumors. There were no differences in GPx4 level between surrounding and tumor tissues in S1 subclass.

Thus, data from human HCC and specifically from S2 molecular HCC subclass largely support experimental
A
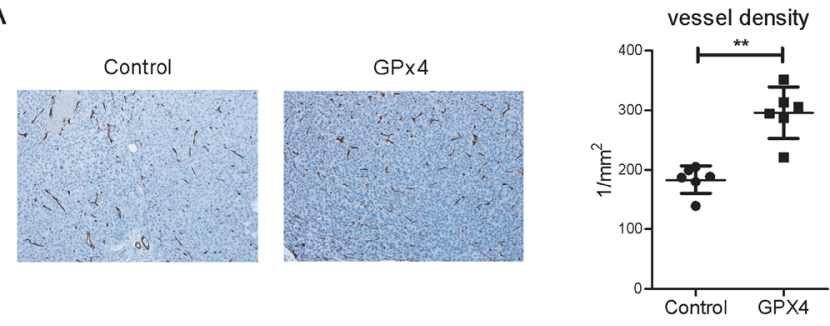
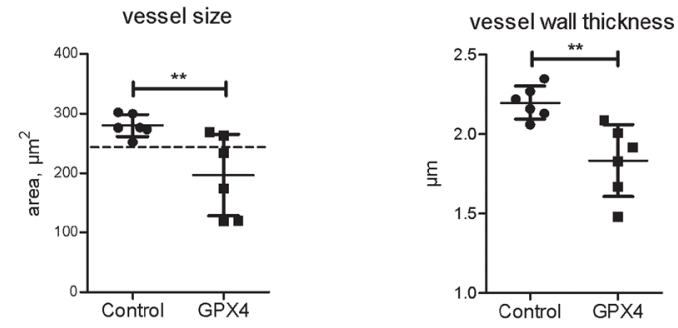
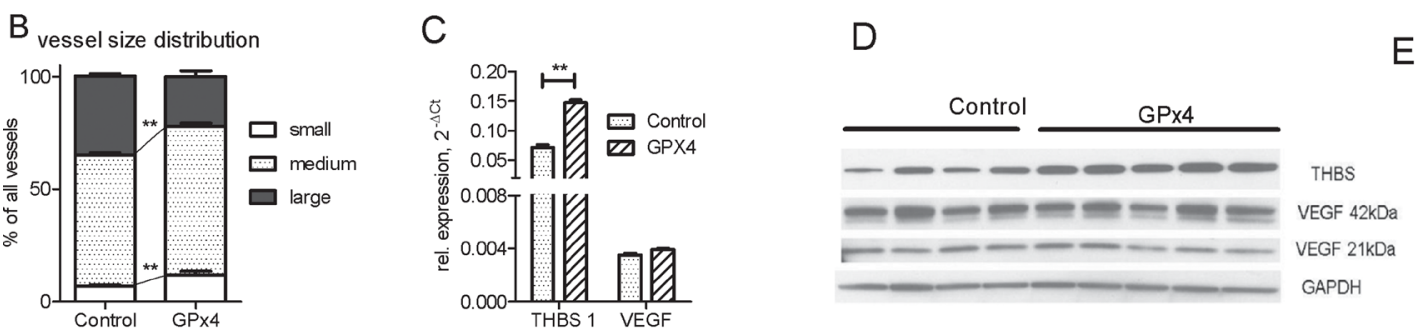

$E$

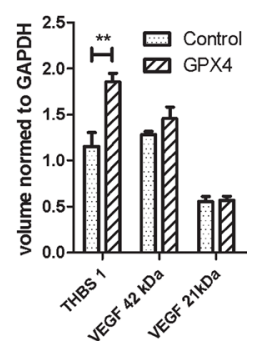

Figure 4: Angiogenesis in control and GPx 4 overexpressing xenograft tumors. (A) A representative endomucin vessel staining and histomorphometric analysis of vessel density, size and wall thickness in GPx 4 overexpressing and control xenograft tumors, $n=6$ per group, $p<0.01$. (B) Impact of GPx4 overexpression on vessel size distribution: mean percentage of large, medium and small vessels was calculated for each group, $n=6$ in each group, ${ }^{* *} p<0.01$. Real-time RT-PCR $(\mathbf{C})$, Western blot (D) and western blot quantification of THBS1 and VEGF in lysates of tumors with and without GPx4 overexpression. ${ }^{* *} p<0.01$. 
findings on GPx4 impact on cell proliferation, cytokine release, angiogenesis and immune cell infiltration.

\section{Pathways differentially regulated in HCCs from patients with low and high tumor GPx4 levels}

To analyze the pathways differentially regulated by GPx4 in human HCCs, we stratified patients according to their GPx4 expression levels in tumor, defined quartiles with the high and the low GPx4 expression and applied Ingenuity Pathway Analysis. The results supported our in vitro data and revealed pathways involved in cell migration, adhesion and immune response (Table 1, Supplementary Table 2).

A number of pathways differentially regulated by GPx4 in human HCC deals with immune cell and their transmigration and include diapedesis of granulocytes (neutrophils, basophils and eosinophils)

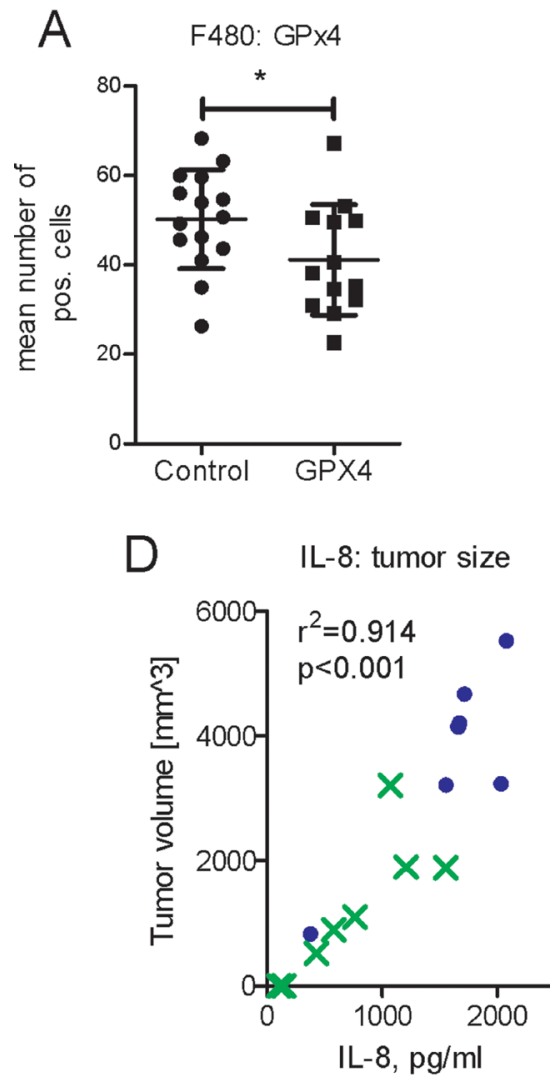

$\mathrm{F}$

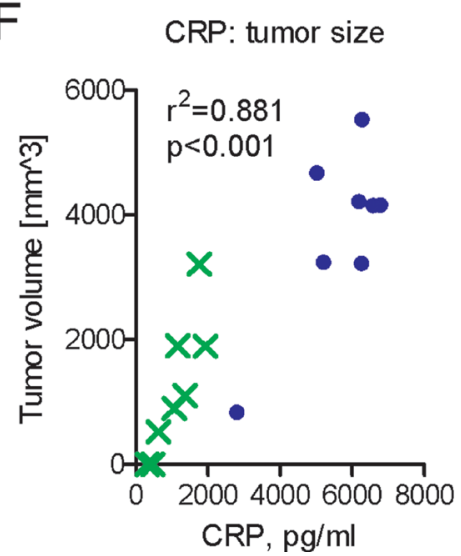

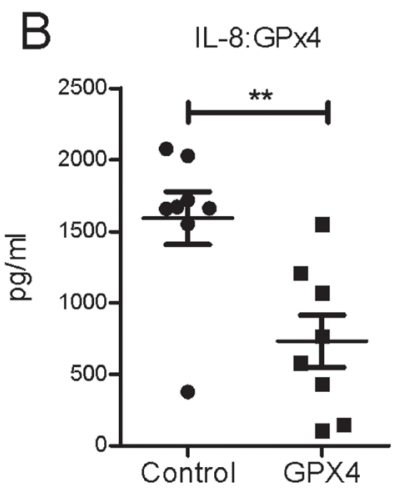
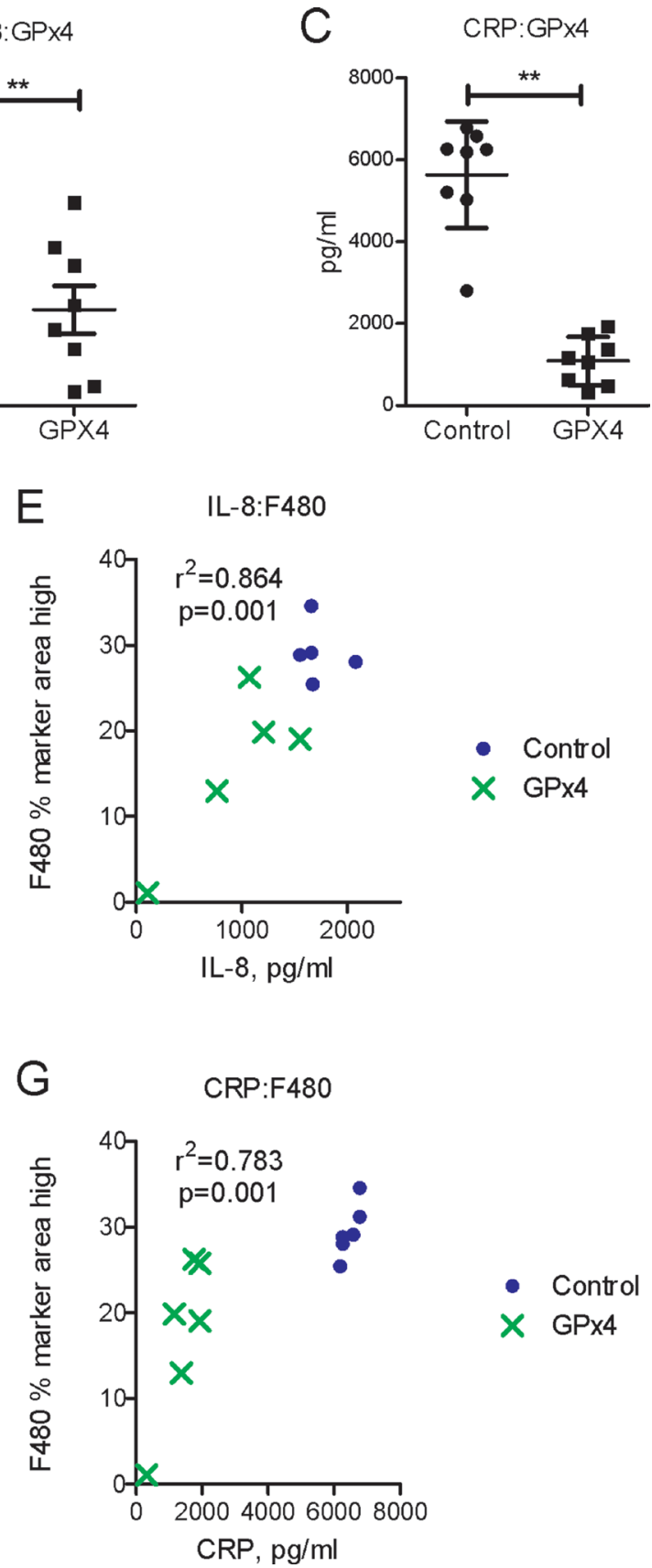

Figure 5: Impact of GPx4 overexpression in tumor cells on macrophage infiltration, IL-8 and C-reactive protein. (A) Histomorphometric analysis of F4/80 positive cells representing macrophages in control (Co) and GPx4 overexpressing tumors (GPx4), $n=$ $13-15,{ }^{*} p<0.05$. Serum protein concentrations of IL-8 (B) and C-reactive protein (CRP) (panel C) in animals bearing GPX4- overexpressing or control tumors ${ }^{*} p<0.05,{ }^{* *} p<0.01, n=8$. Correlations $\left(\mathrm{r}^{2}\right.$ Pearson) of serum IL-8 with tumor size (D) and macrophage infiltration (E) in xenograft model, $n=8$. Correlations of serum CRP with tumor size $(\mathbf{F})$ and macrophage infiltration $(\mathbf{G})$ in xenograft model, $n=8$. 
and agranulocytes ( lymphocytes and monocytes) as well as B cell development and primary immunodeficiency signaling (Table 1). Other two differentially regulated pathways - actin cytoskeleton signaling and integrin- linked kinase (ILK) signaling - further support the involvement of GPx4 in the regulation of cell movement. Finally, pathways involved in hepatic stellate cells activation and fibrosis as well as in thyroid hormone
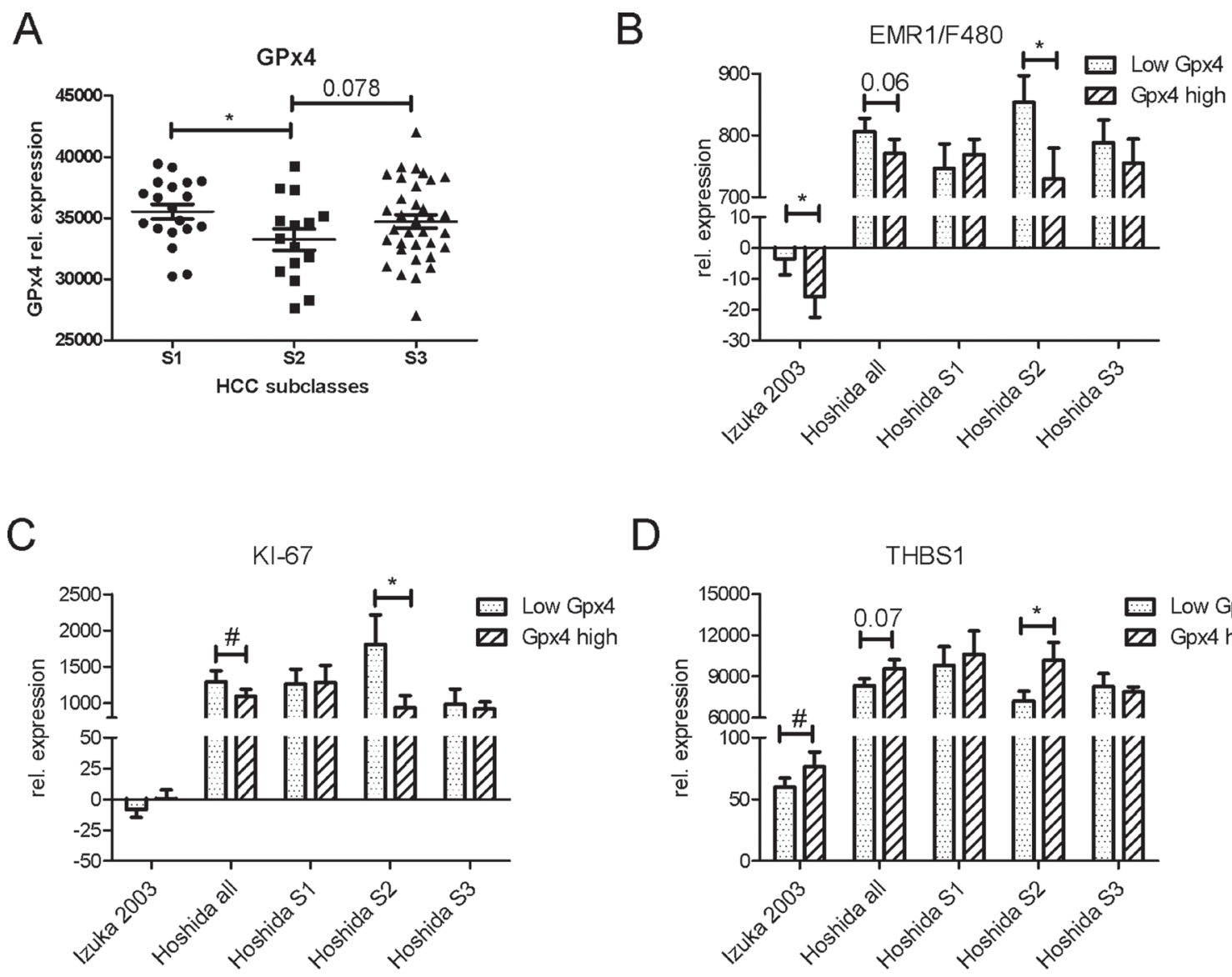

D
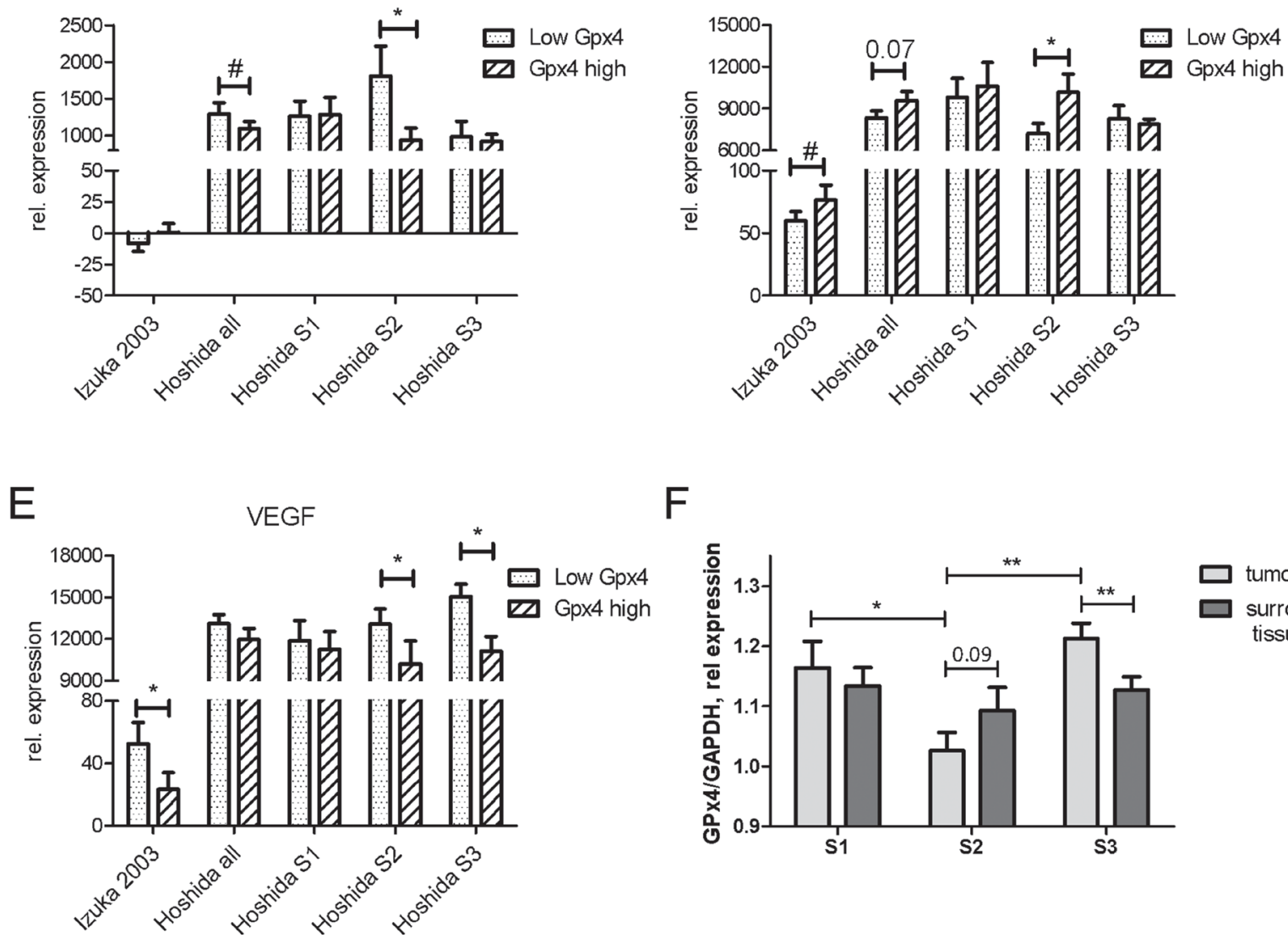

$\mathrm{F}$

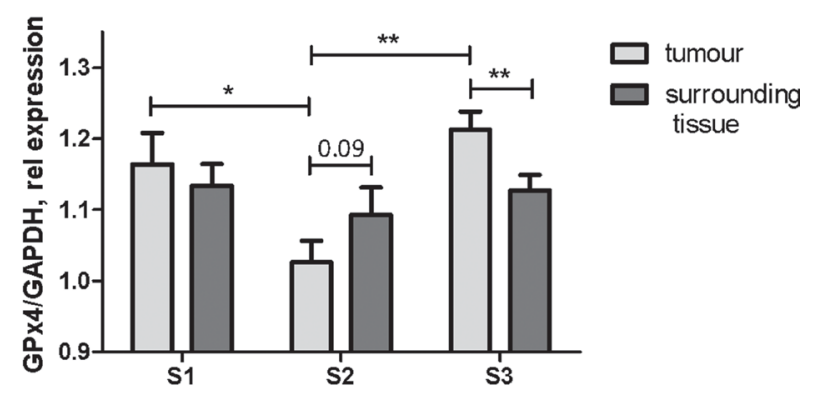

Figure 6: Interactions of GPx4 with gene expression in human HCC patients. Re-evaluation of gene expression microarray data in tumor tissues from two cohorts of human HCC [23, 24]. The cohort of Hoshida was subdivided into molecular subclasses S1, S2 and S3. (A) Expression levels of GP x 4 in tumor tissues of patients from S1, S2 and S3 HCC subclasses. ${ }^{*} p<0.05$ S1 vs S2. The patients were stratified according to the normalized GPx4 expression levels. Mean gene expression values of EMR1/F4/80 (B), KI-67 (C), THBS1 (D), and VEGF (E) were compared between "Low GPx4" or "High Gpx4" patient groups. " $p<0.05$; ${ }^{* *} p<0.01$ Mann-Whitney one-tailed $t$-test; \# variances are different at $p<0.05$. (F) Relative GPx4 expression was compared between HCC tumor tissues and surrounding tissues from the patients with different molecular subclasses of HCC in the Hoshida cohort. ${ }^{*} p<0.05,{ }^{* *} p<0.01$ two sides unpaired $t$-test, $n=18$ for $\mathrm{S} 1, n=9$ for $\mathrm{S} 2, n=26$ for $\mathrm{S} 3$ group. 
receptor / retinoid $\mathrm{X}$ receptor signaling (TR/RXR) also differed between the HCC patients from the highest and the lowest GPx4 expression quartiles. Thus, impact of GPx4 on immune cells in HCC deserves further attention.

\section{Potential effects of GPx4 on immune cells in HCC}

Next, we used a novel CIBERSORT approach to compare the immune cell composition between the low/high GPx4 patient groups. These groups have been previously defined in the preceeding Result sections. CIBERSORT immune cell profile for each patient has been calculated from microarray gene expression data. The results are shown in Figure 7A. We have also compared the mean values for each immune cell type between the low and high GPX4 patient groups (Supplementary Table 3). We found that M0 macrophages, regulatory T cells and activated NK cells were strongly increased whereas eosinophils, $\gamma \delta \mathrm{T}$ cells and activated dendritic cells were depleted in high GPx4 tumors. High GPx4 expression was also associated with a shift from M2 toward M1 macrophages (Supplementary Table 3) characteristic for tumor suppression [20]. We could recapitulate chemoattraction of neutrophils by IL- 8 in our dataset (Supplementary Table 4). However, the percentage of neutrophils, $\mathrm{CD}^{+}$memory resting $\mathrm{T}$ cells, $\mathrm{CD} 8^{+} \mathrm{T}$ cells and monocytes remained constant between the low / high GPx4 groups.

Taking into account expression levels EMR1/ F480 in immune cells [23] and the percentage of each immune cell type, we identified eosinophil and M2 macrophage populations are the main contributors to the reduced EMR1/F4/80 levels in "high GPx4" patients (Supplementary Table 5). Thus, higher expression of GPx4 is associated with a distinct profile of infiltrating immune cells in human HCCs.

\section{DISCUSSION}

The role of selenoenzyme GPx4 in HCC formation is currently unknown. To our knowledge, this is the first study which provides convincing evidences in favor of tumor suppressive function of GPx4 in $\mathrm{HCC}$ specifically in context of highly upregulated proliferation. In particularly, we found that overexpression of GPx4 in HCC cells reduced free radical levels, increased GSH and decreased proliferation (Figure 7C). Moreover, GPx4 reduced formation of the HCC-promoting cytokine IL-8, inhibited cell cycle progression and reduced cell migration after pro-oxidative challenge with linoleic acid hydroperoxide. Importantly, analysis of gene expression data from human HCC tumors recapitulated most of our experimental in vitro and in vivo findings.

Epidemiologically, selenium is highly relevant for $\mathrm{HCC}$ protection in humans in areas with low soil selenium as Europe and China [8-10]. Recently, a cohort within the
EPIC (European Prospective Investigation into Cancer and Nutrition) study showed that decreased plasma selenium is associated with increased risk of HCC [8]. These human data agree with protective role of selenium in progression and promotion phases of experimental HCC [26]. As our mechanistic data suggests, GPx4 significantly contributes to HCC protection by selenium, even if other selenoproteins as SELP, DIO1 and TXNRD2 show similar positive association with cancer survival (Supplementary Table 1) and may also be involved.

GPx4 level in human tissues seems to be tightly regulated suggesting that only a narrow GPx4 range is physiological. Distribution frequency of naturally possible expression levels in different individuals gives us an idea which GPx4 levels are common and thus physiological. Indeed, the distribution width of GPx4 expression is narrow when compared with all genes (NCBI Aceview, Supplementary Figure 8A). For narrow distribution, even relatively small shift in GPx4 expression level may already bring it close to its physiological limit (Supplementary Figure 8A). A narrow physiological distribution of GPx4 expression could be an explanation for the relative small changes in protein and activity increase even using a strong CMV promoter in our experiments. Relatively small changes in GPx4 mRNA levels we have observed in patients are also consistent with the tight GPx4 regulation (Supplementary Figure 8B).

The net impact of GPx4 on HCC biology depends on the molecular context which differs between the molecular HCC subclasses S1, S2 and S3 selected on the basis of similar gene expression patterns [25]. We found that GPx4 insufficiency is particularly relevant for S2 subclass of tumors which is characterized by increased proliferation and WNT-pathway activation.

In contrast to $\mathrm{S} 2$, molecular subclasses $\mathrm{S} 1$ and $\mathrm{S} 3$ might provide a different context for the role of GPx4. For example, accumulation of GPx4 in tumor tissue as compared to surrounding tissue has been described in hepatitis C-related liver tumors [27]. This finding could be retraced in our data for S3 molecular subclass (Figure 6F), which predominates in hepatitis C-related tumors [25]. In addition, even if GPx4 mRNA and protein accumulate, it does not necessarily increase GPx4 activity as the function may still be lost.

\section{Impact of Gpx4 on intracellular radicals, redox status and cell proliferation}

GPx4 plays apparently a fundamental role in the regulation of radical homeostasis and regulates a specific type of cell death called ferroptosis [28]. We have shown that GPx4 overexpression in HCC cells decreased intracellular radicals which, in turn, induce cell proliferation [29]. As GSH can directly scavenge radicals, high glutathione content inhibited tumor cell proliferation in rat HCC model [30] and might thus contribute to the anti-proliferative GPx4 effects. 
Table 1: Differentially regulated canonical pathways between the lowest and the highest quartile of GPx4 expression in tumor tissue of HCC patients

\begin{tabular}{cccc}
\hline Ingenuity Canonical Pathways & $\begin{array}{c}-\log (\mathbf{p}- \\
\text { value })\end{array}$ & Ratio & Molecules \\
\hline $\begin{array}{c}\text { Hepatic Fibrosis / Hepatic Stellate Cell } \\
\text { Activation }\end{array}$ & $9,44 \mathrm{E} 00$ & $4,92 \mathrm{E}-02$ & $\begin{array}{c}\text { COL6A1, COL6A3, COL6A2, CCL21, IGFBP5, } \\
\text { MYH11, COL4A2, COL15A1, COL3A1 }\end{array}$ \\
Granulocyte Adhesion and Diapedesis & $5,46 \mathrm{E} 00$ & $3,39 \mathrm{E}-02$ & CCL21, CXCL12, THY1, CCL14, CCL19, SELPLG \\
Agranulocyte Adhesion and Diapedesis & $5,3 \mathrm{E} 00$ & $3,17 \mathrm{E}-02$ & CCL21, CXCL12, CCL14, MYH11, CCL19, SELPLG \\
Primary Immunodeficiency Signaling & $3,61 \mathrm{E} 00$ & $5,77 \mathrm{E}-02$ & IL7R, IGHG3, IGKC \\
B Cell Development & $2,54 \mathrm{E} 00$ & $5,88 \mathrm{E}-02$ & IL7R, IGKC \\
Atherosclerosis Signaling & $2,51 \mathrm{E} 00$ & $2,42 \mathrm{E}-02$ & CXCL12, COL3A1, SELPLG \\
Hematopoiesis from Pluripotent Stem & $2,2 \mathrm{E} 00$ & $3,92 \mathrm{E}-02$ & IGHG3, IGKC \\
$\quad \begin{array}{c}\text { Cells } \\
\text { ILK Signaling }\end{array}$ & $2,03 \mathrm{E} 00$ & $1,61 \mathrm{E}-02$ & VIM, MYH11, TMSB10/TMSB4X \\
Leukocyte Extravasation Signaling & $1,95 \mathrm{E} 00$ & $1,52 \mathrm{E}-02$ & CXCL12, THY1, SELPLG \\
Actin Cytoskeleton Signaling & $1,85 \mathrm{E} 00$ & $1,38 \mathrm{E}-02$ & F2R, MYH11, TMSB10/TMSB4X \\
Systemic $\quad$ Lupus Erythematosus & $1,83 \mathrm{E} 00$ & $1,36 \mathrm{E}-02$ & IGHG3, IGKC, C7 \\
$\quad \begin{array}{c}\text { Signaling } \\
\text { TR/RXR Activation }\end{array}$ & $1,77 \mathrm{E} 00$ & $2,35 \mathrm{E}-02$ & TCF4, COL6A3 \\
Factors Promoting Cardiogenesis in & $1,71 \mathrm{E} 00$ & $2,17 \mathrm{E}-02$ & \\
Vertebrates & & &
\end{tabular}

In vivo, transplanted GPx4-overexpressing $\mathrm{HCC}$ cells formed smaller tumors which displayed reduced tumor cell proliferation and reduced macrophage density.

In agreement with our findings in $\mathrm{HCC}$, GPx4 inhibits cell cycle progression and decrease growth of xenograft tumors also in non-HCC cancer cells [31,32]. GPx4 per se attenuates tolerance towards oxidative stress $[33,34]$ or synergizes with the lipophilic radical scavenger vitamin $\mathrm{E}$ in hepatocytes [35].

Lipid hydroperoxides are substrates of GPx4 and originate from both enzymatic (lipoxygenases, cyclooxygenases) and non-enzymatic (free radicals) lipid peroxidation. Polyunsaturated fatty acids-e.g. linoleic acid - are particularly prone to radical-induced peroxidation. Peroxidized linoleic acid ( $\mathrm{LOOH})$ is crucial for pathogenesis of both, non-alcoholic steatohepatitis (NASH) and HCC $[7,36]$ and provides a relevant context for protective GPx4 activity.

\section{Impact of GPx4 overexpression on tumor angiogenesis and infiltrating immune cells}

Overexpression of GPx4 in HCC cells reduced proangiogenic IL-8 and enhanced anti-angiogenic THBS1 levels and altered angiogenic pattern in tumors. GPx4overespressign tumors showed reduced percentage of large vessels and thinner vessel walls. In line with our findings here, GPx4 deficiency in tumors increased angiogenesis [37].

Here, we discovered that GPx4 consistently increases THBS1 levels in vitro and in vivo, just in agreement with human HCC data showing the same positive correlation. THBS1 is a potent endogenous inhibitor of angiogenesis, blocks nitric oxide-driven vascular smooth muscle cells relaxation and is involved in HCC [19]. THBS1 upregulation together with the impaired migration of endothelial cells might be the mechanisms how GPx4 inhibits tumor angiogenesis. Indeed, THBS1 overexpression led to a decreased average vessel size and a reduced percentage of large vessels [38] - all the features also observed in GPx4 - overexpressing tumors.

We observed a clear linear correlation between the percentage of large vessels and vessel wall thickness (Supplementary Figure 3A) that may reflect retained physiological normality of tumor vessels and indicate the intact pericyte coverage [39].

We have showed that high GPx4 expression in human HCC is associated with a distinct composition of infiltrating immune cells: $\gamma \delta \mathrm{T}-$-cells, eosinophils and activated dendritic cells were reduced, whereas M1macrophages, activated NK-cells and regulatory T-cells were increased. 
Such a composition of infiltrating immune cells might be beneficial. Indeed, $\gamma \delta \mathrm{T}$ cells favour development of HCC [40], although tumor suppressive functions have been described in other cancer types. In addition, M1macrophages are anti-tumorigenic and positively correlate with survival of HCC patients [41].
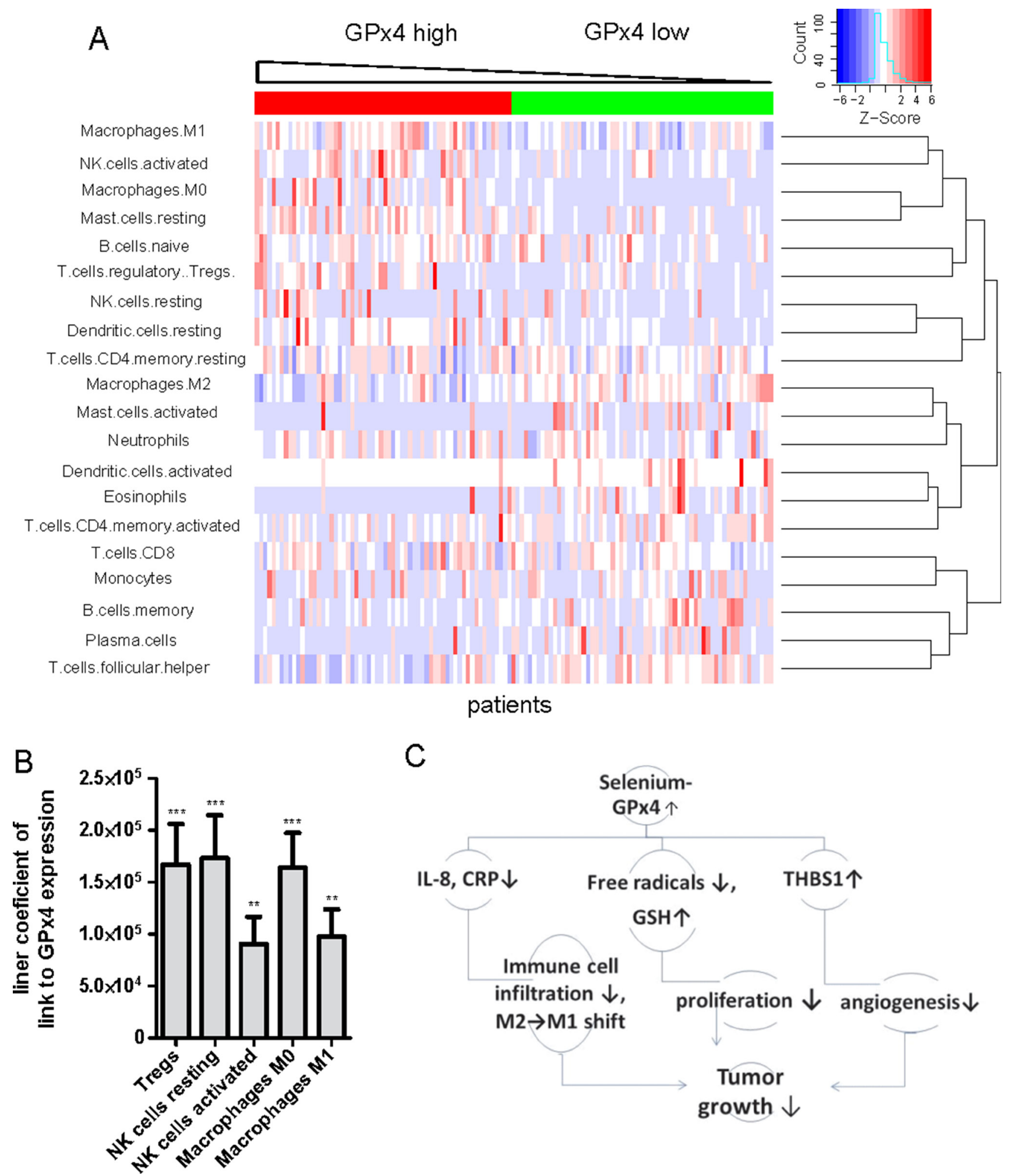

C

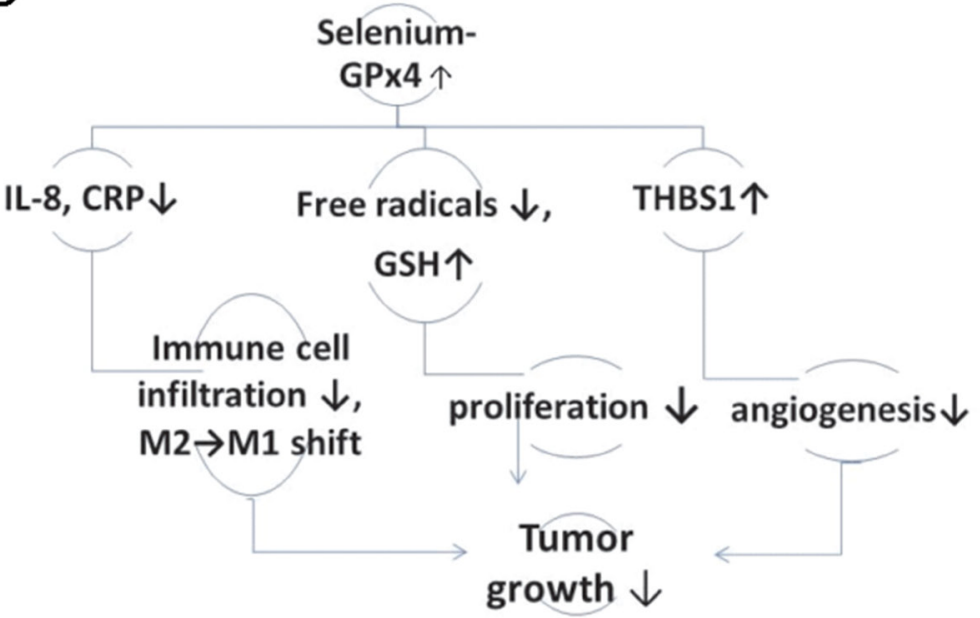

Figure 7: GPx4 expression level and profiles of tumor infiltrating immune cells in human HCC. (A) Heat map of the infiltrating immune cells composition as determined by CIBERSORT method in relation to GP x 4 expression level within tumors. Each column represents one patient. (B) Linear coefficients of the regression analysis between amounts of immune cells types and GP $\mathrm{x} 4$ expression levels in patients. ${ }^{* *} p<0.01 ;{ }^{* * *} p<0.0001$ (C) Suggested mechanisms of protection by selenoenzyme GP x 4 in HCC. 
GPx4 overexpression and increased GSH levels may affect not only immune cell composition but also function. In particular, higher levels of thiols can improve the cytotoxic activity of $\mathrm{CD} 8^{+} \mathrm{T}$ cells [42]. These immunecellular mechanisms might also contribute to the inverse correlation between glutathione concentration and tumor size observed in our study.

Collectively, these data suggest that protection by GPx4 in hepatocarcinogenesis is mediated - at least in part - by the improved immune response.

\section{Outlook for clinical implications}

The suggested protective role of GPx4 in hepatocarcinogenesis opens novel preventive and therapeutic strategies. GPx4 mimetics, selenium prodrugs and oral selenium substitution are all potential strategies to increase hepatic GPx4 activity in patients at risk and in those with established HCC. However, genetic polymorphism that affects GPx4 protein synthesis [43] has to be considered.

Previous SELECT study on cancer prevention by selenium did not show any benefits [44]. However, this study involved patients from the USA where soil selenium concentration is higher than in Europe and seems not to be a limiting factor. Consequently, systemic selenium concentrations in patients from the SELECT study $(\sim 130$ $\mathrm{ng} / \mathrm{ml}$ ) were higher as compared to patients at increased HCC risk from the European EPIC study ( $\sim 90 \mathrm{ng} / \mathrm{ml})$ [8]. Therefore, studies on HCC prevention in patients with low selenium are required.

Our data suggest that patients with the S2 molecular subclass of HCC might particularly benefit from therapeutic interventions that increase GPx4 expression. Therefore, molecular classification of HCC and assessment of serum/plasma selenium levels, hepatic GPx4 levels, CRP/IL-8 and radical stress markers [36] should help to identify target populations for therapeutic GPx4 modulation. Interventional enhancement of GPx4 levels might also increase tumor-infiltrating M1 macrophages as an adjuvant tool to enhance immune therapy responses. However, these concepts require further confirmation in future clinical studies.

\section{MATERIALS AND METHODS}

\section{Cellular experiments}

Human HCC-3 cell line (kind gift of Prof. B. Grasl-Kraupp) has been established from the tumor of an Austrian patient [45]; Huh7 were purchased (ATCC). Cells were kept under standard tissue culture conditions and if not otherwise indicated supplied with 50nM sodium selenite. Synthesized LOOH [14] was dispersed by sonication into serum free medium containing $1 \mathrm{mg} / \mathrm{ml}$ fatty acid free BSA. pcDNA3-GPx4 (pocine) construct was a kind gift of Prof. R. Brigelius-Flohé [46] and was transfected into human HCC-3 and Huh7 hepatocarcinoma cells. After growth selection with geneticin, we generated a stable transfected cell lines with GPx4 overexpression as confirmed by real-time PCR, western blotting, and activity measurements. Control cells were transfected with empty pcDNA3 vector and subjected to the same selection procedure. Cells with the same passage number were used for comparison between control and GPx4 overexpression and no more than 25 passages were conducted. The cells were regularly checked for mycoplasma contaminations.

$2^{\prime}, 7^{\prime}$-dichlorofluorescin diacetate (DCFH) fluorescence, glutathione concentration and cell cycle were analysed as described earlier [18, 47].

\section{Animal xenograft models}

$5 \times 10^{6} \mathrm{HCC}-3$ or $1 \times 10^{6} \mathrm{Huh} 7$ cells (in $200 \mu \mathrm{l}$ of a 1:1vol/vol PBS/matrigel) were injected subcutaneously into each flank of 13-15 weeks old male NSG (NOD scid $\gamma$ ) mice and formed tumors within 4-7 weeks. The experiments were performed with agreement of the local ethical committee.

\section{Patient data}

Microarray gene expression and survival data of cancer patient from the established Prediction of Clinical Outcome from Genomic Profiles (PRECOG) database [23] were used. PRECOG contains survival data from $\sim 18000$ patients diagnosed with 39 distinct malignancies including HCC.

Affimetrix gene expression datasets from two HCC patient cohorts have been re-evaluated: sixty patients from the cohort of Iizuka [24] and eighty patients from the cohort of Hoshida [25].

\section{Free radical detection by electron spin resonance (ESR)}

$10^{6}$ cells $/ \mathrm{ml}$ suspended in PBS containing $100 \mu \mathrm{M}$ DTPA were mixed with $10 \mu \mathrm{l}$ of $20 \mathrm{mM} \mathrm{CMH}$ and analyzed using Bruker ESR spectrometer ESP300e. $100 \mu \mathrm{M}$ DTPA did not affect viability of HCC-3 cells (Supplementary Figure 1). See Supplementary Methods for more details.

\section{Quantification of infiltrating immune cells}

The quantification of infiltrating immune cells in human HCCs has been performed by CIBERSORT method $[23,48]$. CIBERSORT allows enumeration of 22 immune cell types by applying signatures from $\sim 500$ marker genes to microarray gene expression data from tumors to quantify the contribution of each cell type [48]. The method has been previously validated by flow cytometry [48]. 


\section{Immunohistochemistry}

F4/80 and KI-67 staining was applied to analyse macrophage infiltration and cell proliferation respectively. To visualise vessel formation, HCC tissues were stained for endomucin (Endomucin-Ab, eBiosciences, No. 14-5851-81, 1:500) according to [49] and digitalised using a Pannoramic Midi Slide Scanner (3Dhistech, Budapest, Hungary). Quantitative characteristics of vessel morphology were obtained by histomorphometric analyses of digitized slides using the Tissue Studio ${ }^{\circledR}$ software (Definiens, Munich, Germany).

\section{Real time RT-PCR and western blotting}

mRNA was isolated, converted to cDNA and analysed by real time RT-PCR Taqman System as published earlier [7] using the following primers: Hs00173626_m1 for VEGF, Hs00174103 m1 for IL-8, Hs01591589 m1 for GPx2 and Hs00157812_m1 for Gpx4, Hs00357041_m1 for CRP, Mm04207460_m1 for CXCL1 (Applied Biosystems). Western blotting was described earlier [7, 50]. GPx4 polyclonal antibody (Cayman Chemicals No.10005258) detected both porcine and human GPx4.

\section{ELISA protein measurements}

ELISA kits for human serum Quantikine VEGF (R\&D Systems, Abingdon, UK), IL-8 (BenderMedSystems GmbH, Vienna, Austria), CRP (Abcam, Cambrodge, UK) and THBS1 (R\&D Systems, Abingdon, UK) were all used according to the manufacturers' instructions.

\section{Statistics}

If not otherwise indicated, all cellular data were obtained from $n=5$ independent experiments. Data are expressed as mean $\pm \mathrm{SD}$, and statistical differences were determined using ANOVA with significance accepted at $p<0.05$.

\section{Precis}

We have identified selenoenzyme GPx4 as a potential target in a proliferation subclass of liver cancers with impact on proliferation, angiogenesis and immune cell profiling. These findings are based on in vitro and in vivo data and include two generated hepatocarcinoma GPx4-overexpressing cell lines together with microarray gene expression analysis of human hepatocarcinomas. The obtained mechanistic data provide useful knowledge for future personalized medicine strategies.

\section{Abbreviations}

$\mathrm{CMH}$ - 1-Hydroxy-3-methoxycarbonyl-2,2,5,5tetramethylpyrrolidine . $\mathrm{HCl} ; \mathrm{CRP}-\mathrm{C}$-reactive protein; CXCL1 -chemokine (C-X-C motif) ligand 1; DCFH - 2',7'-dichlorofluorescin diacetate; DTPA Diethylenetriaminepentaacetic acid; EMR1 - adhesion $\mathrm{G}$ protein-coupled receptor E1 (human); F4/80 adhesion G protein-coupled receptor E1 (mouse); GPx - glutathione peroxidase; GSH - glutathione (reduced); IL-8 - interleukin 8; FCS - fetal calf serum; HCC hepatocellular carcinoma; LDH - lactate dehydrogenase; LH - linoleic acid; $\mathrm{LOOH}$ - linoleic acid hydroperoxides; ROS - reactive oxygen species; THBS1 - thrombospondin 1; VEGF - vascular endothelial growth factor; NSG NOD scid $\gamma$ (NOD.Cg-Prkdcscid Il2rgtm1 Wjl/SzJ).

\section{Author contributions}

study concept and design: NRU, DS, RE, MPR, RSH ; acquisition of data: NRU, EB, DS, MS, HH, KS, GT; analysis and interpretation of data: NRU, MP, TR, MS, HH, GT, RE; drafting of the manuscript: NRU, RE, RSH, DS, TR; critical revision of the manuscript for important intellectual content: RSH, TR, HH, MS, KS, GT, RE, DS, MT, MPR; statistical analysis: NRU, GT, HH, MS; obtained funding: NRU; technical or material support: KS, MP, HH, GT, MS, EB, DS; study supervision: NRU, MPR, MT, DS

\section{ACKNOWLEDGMENTS AND FUNDING}

We thank Dr. A. Alisadeh and Dr. A. Gentles from the Stanford University, USA, for providing access to Cibersort and Precog platforms as well as for the permission to use the obtained results; Mrs. Wen Li, Mag. Maximilian Wohlgenannt, Dr. Philipp Schwabl and Mrs. Lisa Nika for their excellent assistance in animal experiments. We also thank Mr. Maxim Novoseltsev for his help in creating of the heat map (Figure 7A) as well as for the related calculations. We are also very grateful to Prof. Regina Brigelius-Flohé for providing pcDNA3GPX4 construct as well as to Mag. C. Seif and Dr. Ch. Brostjan for providing THBS1 antibody. This work was supported by a grant from Herzfelder Familienstiftung to N.R.U., project No. AP00585OFF.

\section{CONFLICTS OF INTEREST}

None.

\section{REFERENCES}

1. Llovet JM, Villanueva A, Lachenmayer A, Finn RS. Advances in targeted therapies for hepatocellular carcinoma in the genomic era. Nat Rev Clin Oncol. 2015; 12:408-424.

2. Cohen JC, Horton JD, Hobbs HH. Human fatty liver disease: old questions and new insights. Science. 2011; 332:1519-1523.

3. Matter MS, Marquardt JU, Andersen JB, Quintavalle C, Korokhov N, Stauffer JK, Kaji K, Decaens T, 
Quagliata L, Elloumi F, Hoang T, Molinolo A, Conner $\mathrm{EA}$, et al. Oncogenic driver genes and the inflammatory microenvironment dictate liver tumor phenotype. Hepatology. 2016; 63:1888-1899.

4. Marra M, Sordelli IM, Lombardi A, Lamberti M, Tarantino L, Giudice A, Stiuso P, Abbruzzese A, Sperlongano R, Accardo M, Agresti M, Caraglia M, Sperlongano P. Molecular targets and oxidative stress biomarkers in hepatocellular carcinoma: an overview. J Transl Med. 2011; 9:171.

5. Udilova N, Jurek D, Marian B, Gille L, Schulte-Hermann $\mathrm{R}$, Nohl H. Induction of lipid peroxidation in biomembranes by dietary oil components. Food and Chemical Toxicology. 2003; 41:1481-1489.

6. Boehm T, Sagmeister S, Berger H, Daryabeigi A, Haslinger E, Murkovic M, Rohr-Udilova N, Stolze K, Huber W, Grasl-Kraupp B. Peroxidized Fatty Acids May Induce A Pro-Inflammatory Response In The Liver And May Trigger The Outbreak Of Non-Alcoholic Steatohepatitis (NASH). Journal of Hepatology. 2010; 52:S139.

7. Rohr-Udilova N, Sieghart W, Eferl R, Stoiber D, BjorkhemBergman L, Eriksson LC, Stolze K, Hayden H, Keppler B, Sagmeister S, Grasl-Kraupp B, Schulte-Hermann R, PeckRadosavljevic M. Antagonistic effects of selenium and lipid peroxides on growth control in early hepatocellular carcinoma. Hepatology. 2012; 55:1112-1121.

8. Hughes DJ, Duarte-Salles T, Hybsier S, Trichopoulou A, Stepien M, Aleksandrova K, Overvad K, Tjonneland A, Olsen A, Affret A, Fagherazzi G, Boutron-Ruault MC, Katzke V, et al. Prediagnostic selenium status and hepatobiliary cancer risk in the European Prospective Investigation into Cancer and Nutrition cohort. Am J Clin Nutr. 2016; 104:406-414.

9. Yu MW, Horng IS, Hsu KH, Chiang YC, Liaw YF, Chen CJ. Plasma selenium levels and risk of hepatocellular carcinoma among men with chronic hepatitis virus infection. Am J Epidemiol. 1999; 150:367-374.

10. Yu SY, Zhu YJ, Li WG. Protective role of selenium against hepatitis B virus and primary liver cancer in Qidong. Biol Trace Elem Res. 1997; 56:117-124.

11. Brigelius-Flohe R, Maiorino M. Glutathione peroxidases. Biochim Biophys Acta. 2013; 1830:3289-3303.

12. Mishina NM, Markvicheva KN, Fradkov AF, Zagaynova EV, Schultz C, Lukyanov S, Belousov VV. Chapter Eleven -Imaging H2O2 Microdomains in Receptor Tyrosine Kinases Signaling. In: Enrique C, Lester P, eds. Methods in Enzymology: Academic Press), pp. 175-187.

13. Yant LJ, Ran Q, Rao L, Van Remmen H, Shibatani T, Belter JG, Motta L, Richardson A, Prolla TA. The selenoprotein GPX4 is essential for mouse development and protects from radiation and oxidative damage insults. Free Radic Biol Med. 2003; 34:496-502.

14. Stolze K, Udilova N, Nohl H. Spin trapping of lipid radicals with DEPMPO-derived spin traps: Detection of superoxide, alkyl and alkoxyl radicals in aqueous and lipid phase. Free Radic Biol Med. 2000; 29:1005-1014.
15. Schomburg L, Schweizer U. Hierarchical regulation of selenoprotein expression and sex-specific effects of selenium. Biochim Biophys Acta. 2009; 1790:1453-1462.

16. Chao Y, Li CP, Chau GY, Chen CP, King KL, Lui WY, Yen SH, Chang FY, Chan WK, Lee SD. Prognostic significance of vascular endothelial growth factor, basic fibroblast growth factor, and angiogenin in patients with resectable hepatocellular carcinoma after surgery. Ann Surg Oncol. 2003; 10:355-362.

17. Ren Y, Poon RT, Tsui HT, Chen WH, Li Z, Lau C, Yu WC, Fan ST. Interleukin-8 serum levels in patients with hepatocellular carcinoma: correlations with clinicopathological features and prognosis. Clin Cancer Res. 2003; 9:5996-6001.

18. Rohr-Udilova NV, Stolze K, Sagmeister S, Nohl H, Schulte-Hermann R, Grasl-Kraupp B. Lipid hydroperoxides from processed dietary oils enhance growth of hepatcarcinoma cells. Mol Nutr Food Res. 2008; 52:352-359.

19. Li Y, Turpin CP, Wang S. Role of thrombospondin 1 in liver diseases. Hepatol Res. 2017; 47:186-193.

20. Wan S, Kuo N, Kryczek I, Zou W, Welling TH. Myeloid cells in hepatocellular carcinoma. Hepatology. 2015; 62:1304-1312.

21. Zhou SL, Zhou ZJ, Hu ZQ, Huang XW, Wang Z, Chen EB, Fan J, Cao Y, Dai Z, Zhou J. Tumor-associated neutrophils recruit macrophages and T-regulatory cells to promote progression of hepatocellular carcinoma and resistance to Sorafenib. Gastroenterology. 2017; 150:1646-58.

22. Sieghart W, Pinter M, Hucke F, Graziadei I, Schoniger-Hekele M, Muller C, Vogel W, Trauner M, Peck-Radosavljevic M. Single determination of C-reactive protein at the time of diagnosis predicts long-term outcome of patients with hepatocellular carcinoma. Hepatology. 2013; 57:2224-2234.

23. Gentles AJ, Newman AM, Liu CL, Bratman SV, Feng W, Kim D, Nair VS, Xu Y, Khuong A, Hoang CD, Diehn M, West RB, Plevritis SK, et al. The prognostic landscape of genes and infiltrating immune cells across human cancers. Nat Med. 2015; 21:938-945.

24. Iizuka N, Oka M, Yamada-Okabe H, Nishida M, Maeda Y, Mori N, Takao T, Tamesa T, Tangoku A, Tabuchi H, Hamada K, Nakayama H, Ishitsuka H, et al. Oligonucleotide microarray for prediction of early intrahepatic recurrence of hepatocellular carcinoma after curative resection. Lancet. 2003; 361:923-929.

25. Hoshida Y, Nijman SM, Kobayashi M, Chan JA, Brunet JP, Chiang DY, Villanueva A, Newell P, Ikeda K, Hashimoto M, Watanabe G, Gabriel S, Friedman SL, et al. Integrative transcriptome analysis reveals common molecular subclasses of human hepatocellular carcinoma. Cancer Res. 2009; 69:7385-7392.

26. Bjorkhem-Bergman L, Torndal UB, Eken S, Nystrom C, Capitanio A, Larsen EH, Bjornstedt M, Eriksson LC. Selenium prevents tumor development in a rat model for chemical carcinogenesis. Carcinogenesis. 2005; 26:125-131. 
27. Guerriero E, Capone F, Accardo M, Sorice A, Costantini M, Colonna G, Castello G, Costantini S. GPX4 and GPX7 over-expression in human hepatocellular carcinoma tissues. Eur J Histochem. 2015; 59:2540.

28. Yang WS, SriRamaratnam R, Welsch ME, Shimada K, Skouta R, Viswanathan VS, Cheah JH, Clemons PA, Shamji AF, Clish CB, Brown LM, Girotti AW, Cornish VW, et al. Regulation of ferroptotic cancer cell death by GPX4. Cell. 2014; 156:317-331.

29. Hussain SP, Hofseth LJ, Harris CC. Radical causes of cancer. Nat Rev Cancer. 2003; 3:276-285.

30. Nishikawa-Ogawa M, Wanibuchi H, Morimura K, Kinoshita A, Nishikawa T, Hayashi S, Yano Y, Fukushima S. N-acetylcysteine and S-methylcysteine inhibit MeIQx rat hepatocarcinogenesis in the post-initiation stage. Carcinogenesis. 2006; 27:982-988.

31. Liu J, Du J, Zhang Y, Sun W, Smith BJ, Oberley LW, Cullen JJ. Suppression of the malignant phenotype in pancreatic cancer by overexpression of phospholipid hydroperoxide glutathione peroxidase. Hum Gene Ther. 2006; 17:105-116.

32. Heirman I, Ginneberge D, Brigelius-Flohe R, Hendrickx N, Agostinis P, Brouckaert P, Rottiers P, Grooten J. Blocking tumor cell eicosanoid synthesis by GP x 4 impedes tumor growth and malignancy. Free Radic Biol Med. 2006; 40:285-294.

33. Garry MR, Kavanagh TJ, Faustman EM, Sidhu JS, Liao R, Ware C, Vliet PA, Deeb SS. Sensitivity of mouse lung fibroblasts heterozygous for $\mathrm{GPx} 4$ to oxidative stress. Free Radic Biol Med. 2008; 44:1075-1087.

34. Ran Q, Liang H, Gu M, Qi W, Walter CA, Roberts LJ 2nd, Herman B, Richardson A, Van Remmen H. Transgenic mice overexpressing glutathione peroxidase 4 are protected against oxidative stress-induced apoptosis. J Biol Chem. 2004; 279:55137-55146.

35. Carlson BA, Tobe R, Yefremova E, Tsuji PA, Hoffmann VJ, Schweizer U, Gladyshev VN, Hatfield DL, Conrad M. Glutathione peroxidase 4 and vitamin E cooperatively prevent hepatocellular degeneration. Redox Biol. 2016; 9:22-31.

36. Feldstein AE, Lopez R, Tamimi TA, Yerian L, Chung YM, Berk M, Zhang R, McIntyre TM, Hazen SL. Mass spectrometric profilingof oxidized lipid products in human nonalcoholic fatty liver disease and nonalcoholic steatohepatitis. J Lipid Res. 2010; 51:3046-3054.

37. Schneider M, Wortmann M, Mandal PK, Arpornchayanon W, Jannasch K, Alves F, Strieth S, Conrad M, Beck $\mathrm{H}$. Absence of glutathione peroxidase 4 affects tumor angiogenesis through increased 12/15-lipoxygenase activity. Neoplasia. 2010; 12:254-263.

38. Streit M, Velasco P, Brown LF, Skobe M, Richard L, Riccardi L, Lawler J, Detmar M. Overexpression of thrombospondin-1 decreases angiogenesis and inhibits the growth of human cutaneous squamous cell carcinomas. Am J Pathol. 1999; 155:441-452.
39. Goel S, Duda DG, Xu L, Munn LL, Boucher Y, Fukumura D, Jain RK. Normalization of the vasculature for treatment of cancer and other diseases. Physiol Rev. 2011; 91:1071-1121.

40. Ma S, Cheng Q, Cai Y, Gong H, Wu Y, Yu X, Shi L, Wu D, Dong C, Liu H. IL-17A produced by gammadelta T cells promotes tumor growth in hepatocellular carcinoma. Cancer Res. 2014; 74:1969-1982.

41. Rohr-Udilova N, Trauner M, Peck-Radosavljevic M. Profiling of infiltrating immune cell in tumor tissue of hepatocellular carcinoma patients. J Hepatol. 2016; 64:S572-S573.

42. Kesarwani P, Al-Khami AA, Scurti G, Thyagarajan K, Kaur N, Husain S, Fang Q, Naga OS, Simms P, Beeson G, Voelkel-Johnson C, Garrett-Mayer E, Beeson CC, et al. Promoting thiol expression increases the durability of antitumor T-cell functions. Cancer Res. 2014; 74:6036-6047.

43. Bermingham EN, Hesketh JE, Sinclair BR, Koolaard JP, Roy NC. Selenium-enriched foods are more effective at increasing glutathione peroxidase (GPx) activity compared with selenomethionine: a meta-analysis. Nutrients. 2014; 6:4002-4031.

44. Lippman SM, Klein EA, Goodman PJ, Lucia MS, Thompson IM, Ford LG, Parnes HL, Minasian LM, Gaziano JM, Hartline JA, Parsons JK, Bearden JD 3rd, Crawford ED, et al. Effect of selenium and vitamin $\mathrm{E}$ on risk of prostate cancer and other cancers: the Selenium and Vitamin E Cancer Prevention Trial (SELECT). JAMA. 2009; 301:39-51.

45. Sagmeister S, Eisenbauer M, Pirker C, Mohr T, Holzmann K, Zwickl H, Bichler C, Kandioler D, Wrba F, Mikulits W, Gerner C, Shehata M, Majdic O, et al. New cellular tools reveal complex epithelial-mesenchymal interactions in hepatocarcinogenesis. Br J Cancer. 2008; 99:151-159.

46. Muller C, Wingler K, Brigelius-Flohe R. 3'UTRs of glutathione peroxidases differentially affect seleniumdependent mRNA stability and selenocysteine incorporation efficienc. Biol Chem. 2003; 384:11-18.

47. Jurek D, Udilova N, Jozkowicz A, Nohl H, Marian B, Schulte-Hermann R. Dietary lipid hydroperoxides induce expression of vascular endothelial growth factor (VEGF) in human colorectal tumor cells. FASEB J. 2005; 19:97-99.

48. Newman AM, Liu CL, Green MR, Gentles AJ, Feng W, Xu Y, Hoang CD, Diehn M, Alizadeh AA. Robust enumeration of cell subsets from tissue expression profiles. Nat Methods. 2015; 12:453-457.

49. Bramswig KH, Poettler M, Unseld M, Wrba F, Uhrin P, Zimmermann W, Zielinski CC, Prager GW. Soluble carcinoembryonic antigen activates endothelial cells and tumor angiogenesis. Cancer Res. 2013; 73:6584-6596.

50. Sieghart W, Pinter M, Dauser B, Rohr-Udilova N, Piguet AC, Prager G, Hayden H, Dienes HP, Dufour JF, Peck-Radosavljevic M. Erlotinib and sorafenib in an orthotopic rat model of hepatocellular carcinoma. J Hepatol. 2012; 57:592-599. 